\title{
Sociabilidade e Sociedade de Risco: um estudo sobre relações na modernidade
}

CRISTIANO GUEDES*

\section{BAUMAN, Zygmunt. \\ Amor líquido: sobre a fragilidade dos laços humanos. Rio de Janeiro: Jorge Zahar Editor, 2004.}

O livro Amor líquido, de Zygmunt Bauman, tem como objetivo mostrar a aplicabilidade da teoria da modernidade líquida à explicação e compreensão dos relacionamentos estabelecidos entre homens e mulheres na contemporaneidade. Segundo o autor,

"a misteriosa fragilidade dos vínculos humanos, o sentimento de insegurança que ela inspira e os desejos conflitantes (estimulados por tal sentimento) de apertar os laços e ao mesmo tempo mantê-los frouxos, é o que este livro busca esclarecer, registrar e apreender" (BAUMAN, 2004, p. 8).

A intenção de estar junto e ao mesmo tempo não estabelecer relações duradouras é uma das principiais razões da ambivalência característica dos relacionamentos atuais. Tal ambivalência resulta principalmente da instabilidade que impera na modernidade líquida, época de incertezas e inseguranças provenientes do risco que poderá trazer um novo relacionamento diante do qual previsões e mecanismos de controle não se aplicam. Bauman, ao dissecar os líquidos relacionamentos modernos, mostra como a interação entre homens e mulheres reflete uma ordem social pautada por riscos socialmente produzidos.

A escolha dos relacionamentos como objeto de estudo é justificado, segundo Bauman, em virtude das qualidades que possuem e os tornam representativos da sociedade moderna ${ }^{1}$. A impossibilidade de prever quando e como ocorrerá um relacionamento não está restrita a casos de amor. A previsibilidade seguida da possibilidade de exercer controle sobre os diferentes tipos de relações constituintes das sociedades contemporâneas era uma das expectativas em relação à passagem de uma modernidade sólida para uma modernidade líquida. 
"Os tempos modernos encontraram os sólidos pré-modernos em estado avançado de desintegração; e um dos motivos mais fortes por trás da urgência em derretê-los era o desejo, por uma vez, de descobrir ou inventar sólidos de solidez duradoura, solidez em que se pudesse confiar e que tornaria o mundo previsível e, portanto, administrável" (BAUMAN, 2001, p. 10).

O desejo não só deixou de ser concretizado, como a insegurança passou a caracterizar as relações de amor e, como resultado, a ansiedade, a superficialidade e a brevidade dos relacionamentos surgem como mecanismos de defesa empregados na relação com a alteridade.

Diante do risco representado pela decisão de ingressar em relações amorosas, as pessoas têm-se amparado em dois tipos de estratégias de proteção: "fixação" e "flutuação" . A "fixação" pode ser compreendida como uma tentativa de preservar o relacionamento apesar da impossibilidade de controlá-lo. Tratase do
"esforço para emancipar o relacionamento de sentimentos erráticos e vaci- lantes, para assegurar que - aconteça o que acontecer com suas emoções - os parceiros continuem a beneficiar-se dos dons do amor: o interesse, o cuidado, a responsabilidade do outro parceiro. Um esforço para alcançar o estado em que se possa continuar recebendo sem dar mais, ou dando não mais do que o padrão estabelecido exige" (BAUMAN, 1997, p. 115).

Nesse sentido, a pessoa busca evitar a ansiedade e constante possibilidade do fim do relacionamento. Investe-se na "vontade de cuidar e de preservar o objeto cuidado", ainda que exija renúncias ou mesmo implique rotinas, afinal "o eu que ama se expande doando-se ao objeto amado" (BAUMAN, 2004, p. 24). Contudo a rede de proteção criada pode representar aprisionamento, escravidão e fim da relação ${ }^{3}$. Investe-se no exercício da tolerância para lidar com a diferença que a alteridade representa, diferença que deve ser suportada sob pena de resultar no fim do relacionamento.

Os adeptos da "flutuação", entretanto, não apresentam a mesma perseverança. Não estão dispostos a fazer muitas concessões. Pautam-se por princípios de custo-benefício. Tal como nas relações de mercado, conforme os lucros obtidos, o relacionamento continuará recebendo investimentos ou será suspenso ${ }^{4}$. Bauman apresenta a "flutuação" como "a recusa de conceder o caráter árduo da tarefa e o duro trabalho implicado. A estratégia de "cortar as 
próprias perdas", de "não investir dinheiro bom em busca de mau", de desistir de buscar alhures outra tentativa, uma vez que parece que os ganhos caíram abaixo do nível das despesas que se precisa para assegurá-los. Nessa estratégia, escapa-se da insegurança mais do que se luta com ela, na esperança de que se possa encontrar a segurança alhures a custos mais baixos e com esforço menos oneroso" (BAUMAN, 1997, p. 115). A liberdade para se abandonar a relação a qualquer momento é latente, o amor assume a sua face episódica, ou seja, não está alicerçado em compromissos a longo prazo. Privilegia-se o momento em detrimento do futuro, a trajetória do relacionamento não tem importância. Não há qualquer tipo de garantia. A "fixação" e a "flutuação" medeiam, cada uma a seu modo, a tênue fronteira entre segurança e dependência (como um tipo de possessão/escravidão), por um lado, e liberdade e insegurança, por outro. Esses extremos, em torno dos quais podem ser situados os relacionamentos, são responsáveis pela ambivalência que caracteriza o amor.

Outro conceito central na compreensão da análise de Bauman sobre o amor é o de "sociabilidade", que difere do conceito de "socialização", também explorado pelo autor. Ambos devem ser compreendidos a partir da interação com a estrutura social, porém se referem a processos distintos. "A socialização (pelo menos na sociedade moderna) visa a criar um ambiente de ação feito de escolhas passíveis de serem 'desempenhadas discursivamente', que se concentra no cálculo racional de ganhos e perdas" (BAUMAN, 1997, p. 138). De acordo com o conceito de socialização, o futuro possibilitaria a administração das sociedades com vistas à ordem, mediante a superação de obstáculos. Bauman afirma que, durante considerável período, alguns membros da sociologia defenderam essa perspectiva:

"De fato, durante toda a era moderna, muitos (a maioria dos) sociólogos, tomando as idéias dos fortes por idéias fortes, e os sedimentos de longa coerção e doutrinação por leis da história, tenderam a se colocar do lado dos administradores e ter empatia com seu interesse guerreiro pelos obstáculos que se levantaram no caminho que leva à harmonia e à ordem" (BAUMAN, 1997, p. 138).

Segundo essa perspectiva, a liberdade de escolha dos indivíduos é restringida. Existe um propósito comum a ser seguido pela coletividade. A racionalidade é valorada em detrimento da espontaneidade dos indivíduos. A sociabilidade é caracterizada pela ausência de um referencial preestabelecido e pela impossibilidade de se fazer previsões relacionadas às ações dos indivíduos. 
"A socialidade coloca a unicidade acima da regularidade e o sublime acima do racional, sendo, portanto, em geral avessa às regras, tornando o desempenho das regras problemático e cancelando o sentido instrumental da ação" (BAUMAN, 1997, p. 138) .

A sociabilidade é característica da modernidade líquida na qual os indivíduos não mais têm um grupo de referência pelo qual se pautam. Observase a emergência da multidão, na qual os indivíduos compartilham ações baseadas no instante em que se vive e nas condições semelhantes nas quais se encontram. Bauman estabelece diálogo, embora não apresente qualquer referência no decorrer dos textos, com David Riesman, autor de A multidão solitária, onde já se discutia a alteração dos padrões de comportamento da interação entre os indivíduos tendo como cenário a década de 60 e a figura do indivíduo "alterdirigido" (RIESMAN, 1971).

$\mathrm{O}$ risco que passou a permear as relações entre as pessoas na modernidade líquida é outra questão que permeia com destaque a teoria social de Bauman. $\mathrm{O}$ autor sugere que o processo de liquefação, pelo qual passaram a modernidade e sua atual forma fluida e leve, não deve ser confundido com ausência de relações de poder ou mesmo auto-suficiência em relação à vida em sociedade. Bauman afirma:

"nenhum molde foi quebrado sem que fosse substituído por outro; as pessoas foram libertadas de suas velhas gaiolas apenas para ser admoestadas e censuradas caso não conseguissem se realocar, através de seus próprios esforços dedicados, contínuos e verdadeiramente infindáveis, nos nichos préfabricados da nova ordem" (BAUMAN, 2001, p. 13).

Vive-se em meio a uma "sociedade de risco", tal como teorizada por Ulrich Beck $^{6}$. Riscos produzidos socialmente e, por vezes, ironicamente depositados nas costas dos indivíduos que são obrigados a tolerá-los. Essa sociedade de risco exige que a sociologia pesquise as causas sociais responsáveis pelos desafios emergentes na sociedade líquida, favorecendo, assim, que os indivíduos ingressem no processo reflexivo de elaborar "política-vida"7

Amor líquido, ao evidenciar a influência exercida pela modernidade sobre os relacionamentos interpessoais, pode ser considerado um convite à reflexão sobre o desafio de se viver num mundo cada vez mais global e, também, composto de sociedades marcadas pela diversidade. $\mathrm{O}$ autor apresenta os desafios de se fazer políticas locais destinadas à solução de problemas manifestos localmente, 
mas que têm causas globais. "Os verdadeiros poderes que moldam as condições sob as quais todos nós agimos hoje em dia fluem num espaço global, enquanto nossas instituições de ação política permanecem, em seu conjunto, presas ao chão; elas são, tal como antes, locais" (BAUMAN, 2004, p. 122). Bauman sugere a existência de uma elite global influente e possuidora de elevado poder de mobilidade. Tão logo a vida comece a se tornar insuportável em determinado espaço físico, os membros da elite não hesitam em se mudar. A velha morada e os vizinhos são deixados, afinal os vínculos formados eram propositalmente frágeis e não se justificariam diante da qualidade de vida a ser usufruída em outro lugar até que nova mudança se faça necessária.

Adotando uma linguagem quase literária, conceitos como "sociabilidade", "sociedade de risco" e "globalização", já explorados em obras anteriores, são apresentados de forma serena como a fotografia do autor que ilustra a orelha do livro. Amor líquido analisa sociedades modernas a partir dos relacionamentos interpessoais e mostra a relação entre o local e o global na contemporaneidade. A obra pode ser considerada, também, a representante de uma nova forma de se escrever sociologia. A diversidade dos tipos de fonte utilizados, os campos disciplinares com os quais o autor dialoga ou mesmo a abordagem analítica adotada certamente causarão surpresa. Bauman ousou no estilo, mas sem perder a consistência e a clareza características de sua obra, cada vez mais valorada pela sociologia contemporânea.

\section{Referências}

BAUMAN, Z. Ética pós-moderna. São Paulo: Paulus, 1997. . Modernidade líquida. Rio de Janeiro: Jorge Zahar, 2001. . Amor líquido. Rio de Janeiro: Jorge Zahar, 2004.

BECK, U. A reinvenção da política: rumo a uma teoria da modernização reflexiva. In: GIDDENS, A.; BECK, U.; LASH, S. (Orgs.). Modernização reflexiva. São Paulo: Unesp, 1997.

Sobre a incompreendida falta de experiência da genética humana: as consequiências sociais do não saber relativo. In: BONI, L. Etica e genética. Porto Alegre: EDIPUCRS, 1998.

GIDDENS, A. Modernidade e identidade. Rio de Janeiro: Jorge Zahar, 2002. RIESMAN, D. A multidão solitária. São Paulo: Perspectiva, 1971. 


\section{NOTAS}

* Assistente social, mestrando em Sociologia na Universidade de Brasília (UnB); pesquisador associado ao Instituto de Bioética, Direitos Humanos e Gênero (Anis) e bolsista internacional da Fundação Ford. Endereço eletrônico: cguedes@unb.br.

${ }^{1}$ A palavra "qualidades" foi um dos termos utilizados por Bauman na analogia estabelecida entre processos físicos e sociais, para apresentar a teoria da modernidade líquida (BAUMAN, 2001).

${ }^{2}$ Esses conceitos, embora não estejam explicitados no livro Amor líquido, amparam a discussão sobre a volatilidade do amor. Em Ética pós-moderna (BAUMAN, 1997), Bauman esboça o que futuramente seria traduzido como "amor líquido".

${ }^{3}$ Bauman compara o amor ao desejo. O desejo é voltado ao consumo hedonista, porém breve (instantâneo), do objeto almejado. $\mathrm{O}$ amor tem como meta a possessão, ainda que restrinja a liberdade. Ambos têm na concretização dos objetivos a vulnerabilidade dos respectivos objetos.

${ }^{4} \mathrm{O}$ autor cita o depoimento de um entrevistado que ilustra como, atualmente, a tecnologia fornece as ferramentas necessárias à sociabilidade e facilita na tarefa de romper um relacionamento: "Você sempre pode apertar a tecla para deletar. Deixar de responder um e-mail é a coisa mais fácil do mundo" (BAUMAN, 2004, p. 85).

${ }^{5} \mathrm{Na}$ edição brasileira do livro Ética pós-moderna, a palavra correspondente a "sociabilidade" pode ter sido traduzida como "socialidade". Nesta resenha, as duas palavras são empregadas para se referir ao mesmo processo social analisado por Bauman.

${ }^{6} \mathrm{O}$ conceito de "sociedade de risco" foi desenvolvimento por Ulrich Beck e pode ser mais bem compreendido pela leitura de Beck (1997 e 1998).

${ }^{7}$ Política-vida foi um conceito elaborado por Anthony Giddens e se refere à "política de realização do eu, no contexto da dialética do local e do global e do surgimento dos sistemas internamente referidos da modernidade" (GIDDENS, 2002, p. 222). 